\title{
About the Artist: Visesio Poasi Siasan
}

$\mathrm{V}$ isesio Poasi Siasau-or Sio, as he likes to be called-comes from a hereditary guild of Tongan tufunga or tohunga. He self-identifies as a tufunga'i practitioner and draws on Tongan epistemologies as his pathway to understanding things passed down by traditional knowledge keepers. Indeed, his efficacy as an indigenous practitioner is worldly in a contemporary sense within knowing in a traditional sense.

A promising artist of his generation, Sio's creative ambitions are directed toward the sculpted wooden Tongan divinity forms, which he remakes in a range of styles, stances, and materials including Perspex, glass, stone, wood, and bronze. His twenty-first century approach to an old form presents a challenge for contemporary Tongan Christian politics, as he is critical of the Church's negative impact on Tongan stories, thinking, and traditional ways of life. Furthermore, his sculptures carry a message beyond his politics: they hold and express his personal responsibility for teaching specialized knowledge.

Sio's art practice delves into the context of divinity figures in order to explore their making, meaning, and function in Tongan society and the intersection between this type of deity and Christianity. Thus, the form comes with uncertainty regarding its status as a ceremonial object, a postcontact emblem, a symbol of contempt, or something imbued with ancient knowledge. Sio has sympathetically carried the early nineteenth century figures into the present-day, perhaps unwittingly claiming a position for historic circumstance within a milieu of Western happenstance and interpretations of indigenous forms. The vitality found in Sio's sculptures is present, palpable, and physical. These things appeal to our heart, mind, and spirit.

\author{
NGAHIRAKA MASON \\ Auckland Art Gallery Toi O Tāmaki \\ MANULANI ALULI MEYER \\ Te Wānanga o Aotearoa
}

The art featured in this issue can be viewed in full color in the online versions. 


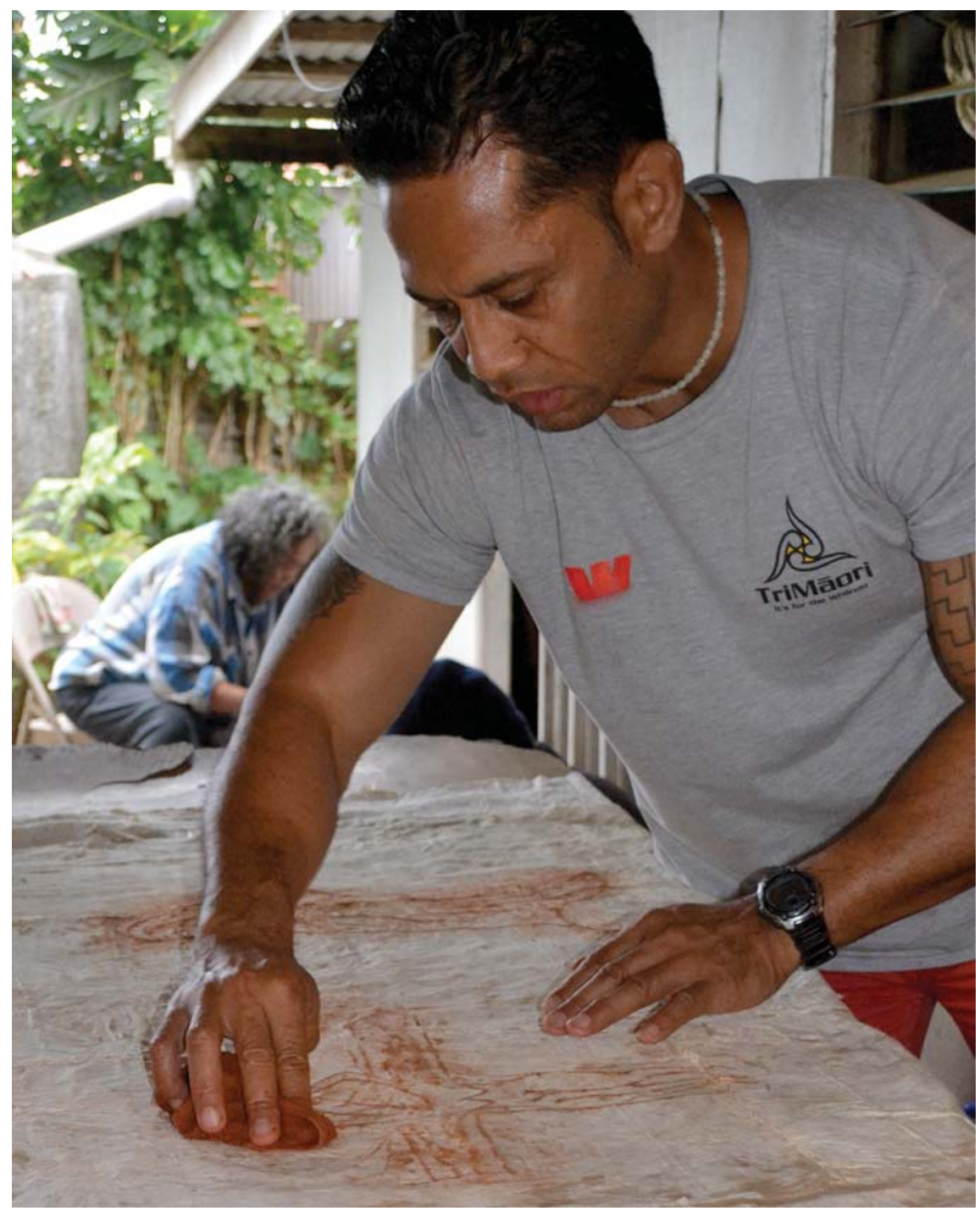

Visesio adorning ngatu (tapa cloth) with imagery of Tongan deities, 20I3.

Visesio is studying for his master's degree at Te Wānanga o Aotearoa in New Zealand. He is a cultural practitioner in He Waka Hiringa, the first Master of Applied Indigenous Knowledge program in the Pacific. As part of his graduate research, Visesio spent several months of 2013 in his home village of Haveluloto, Tonga. He worked with his mother and family members to create his first ngatu, which he decorated with two-dimensional versions of Tongan deities found in his sculptural work. Photo by Serene Tay. 

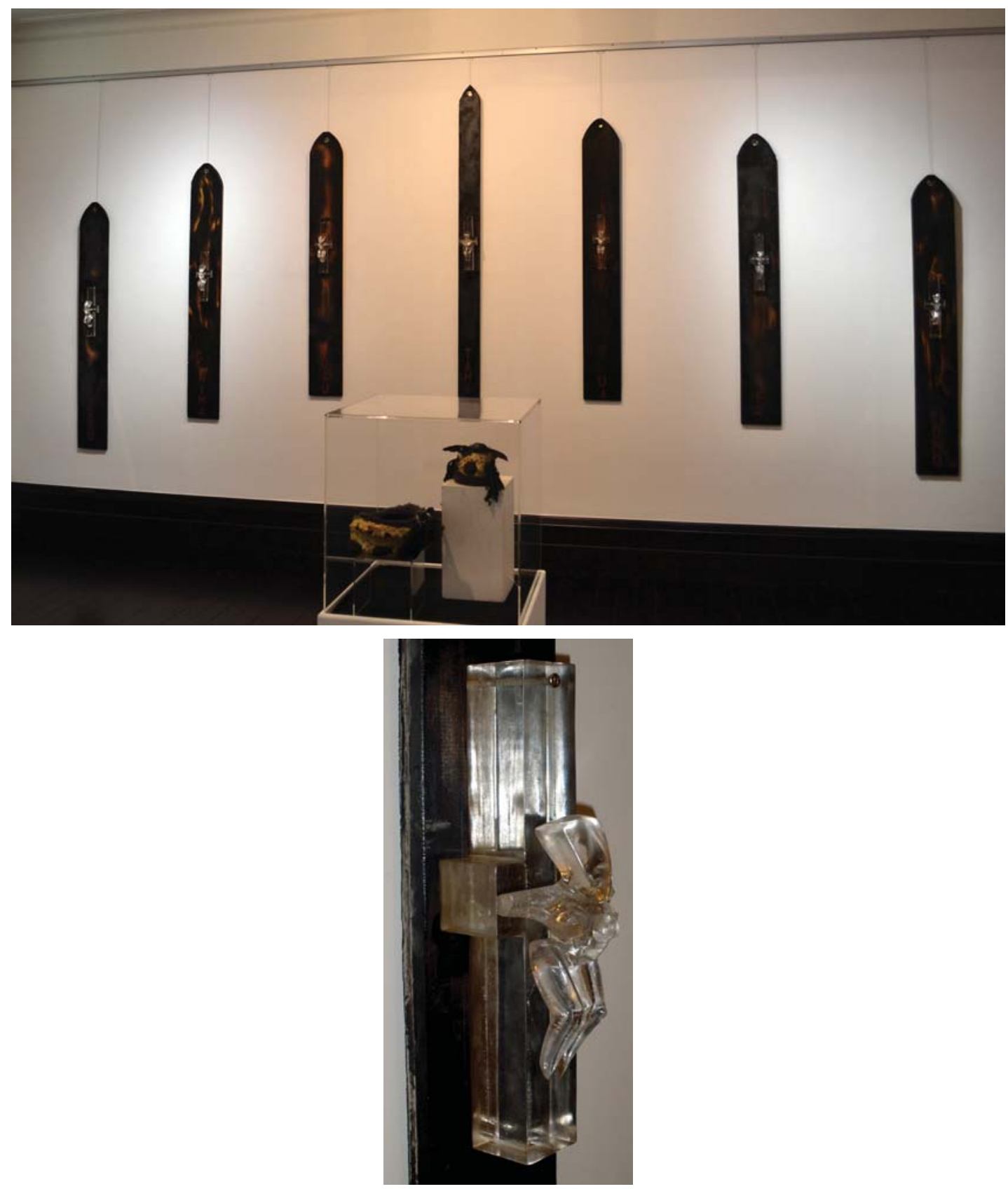

Crucified Tonga, by Visesio Siasau, 2009.

Perspex figures on recycled native timber. I $500-1700 \mathrm{~cm} \times 35 \mathrm{~cm}$. Collection of the artist.

These hermaphroditic figures signify Tongan deities, while their placement-hanging naked on the cross-is a reflection of life in Tonga and the dogmatic dialogue of legitimacy, economy, politics, religions, and education. Photos by Serene Tay. 


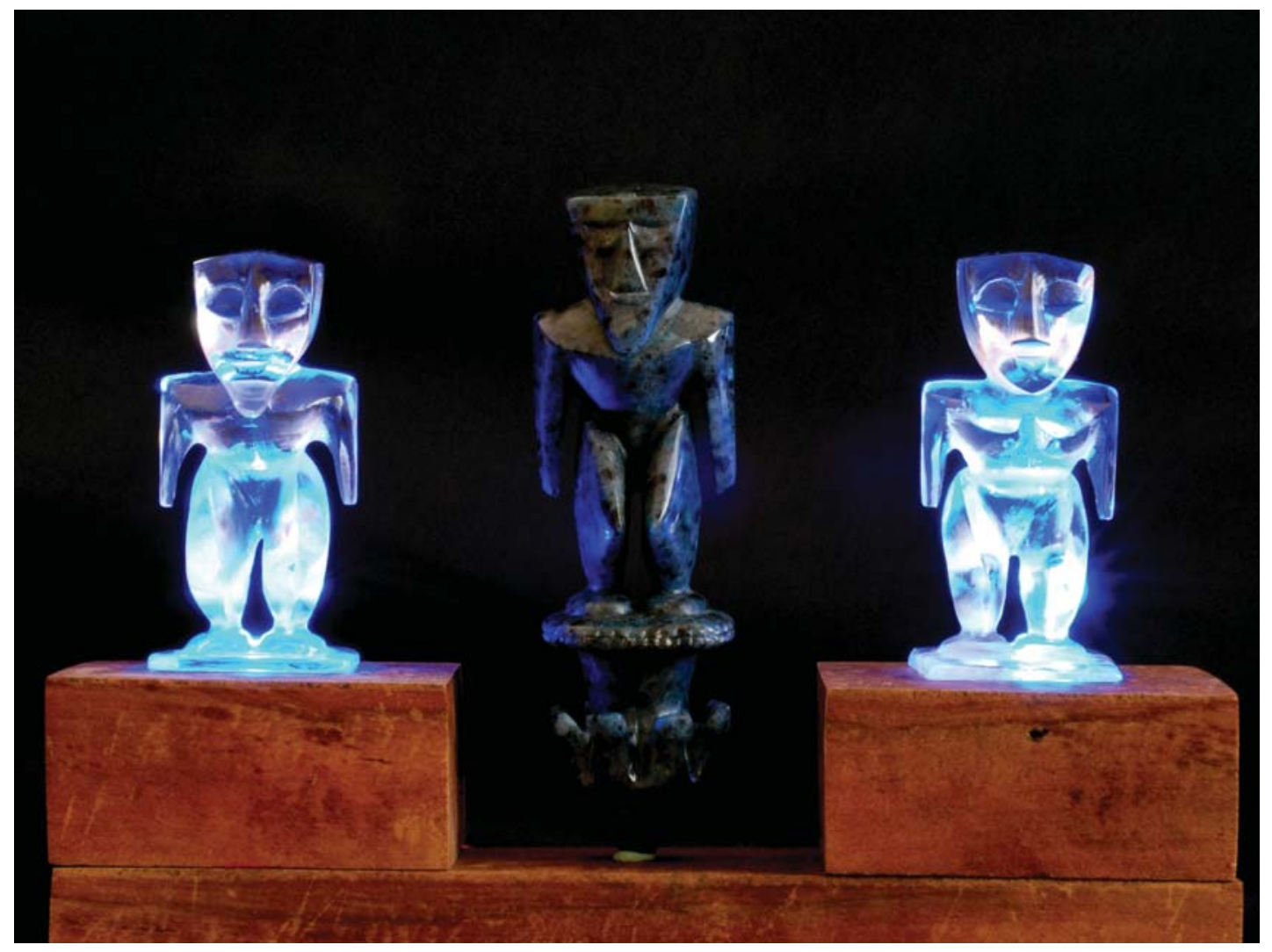

Untitled, by Visesio Siasau, 2009.

Perspex and Corian (center figure) on wood.

Figures $22 \mathrm{~cm} \times$ Io $\mathrm{cm}$. Private collections.

Contemporizing ancient forms brings out the essential beauty and harmony of the divine values of Tongan knowledge and reveals eternal knowledge through encoded forms. Photo by Serene Tay. 


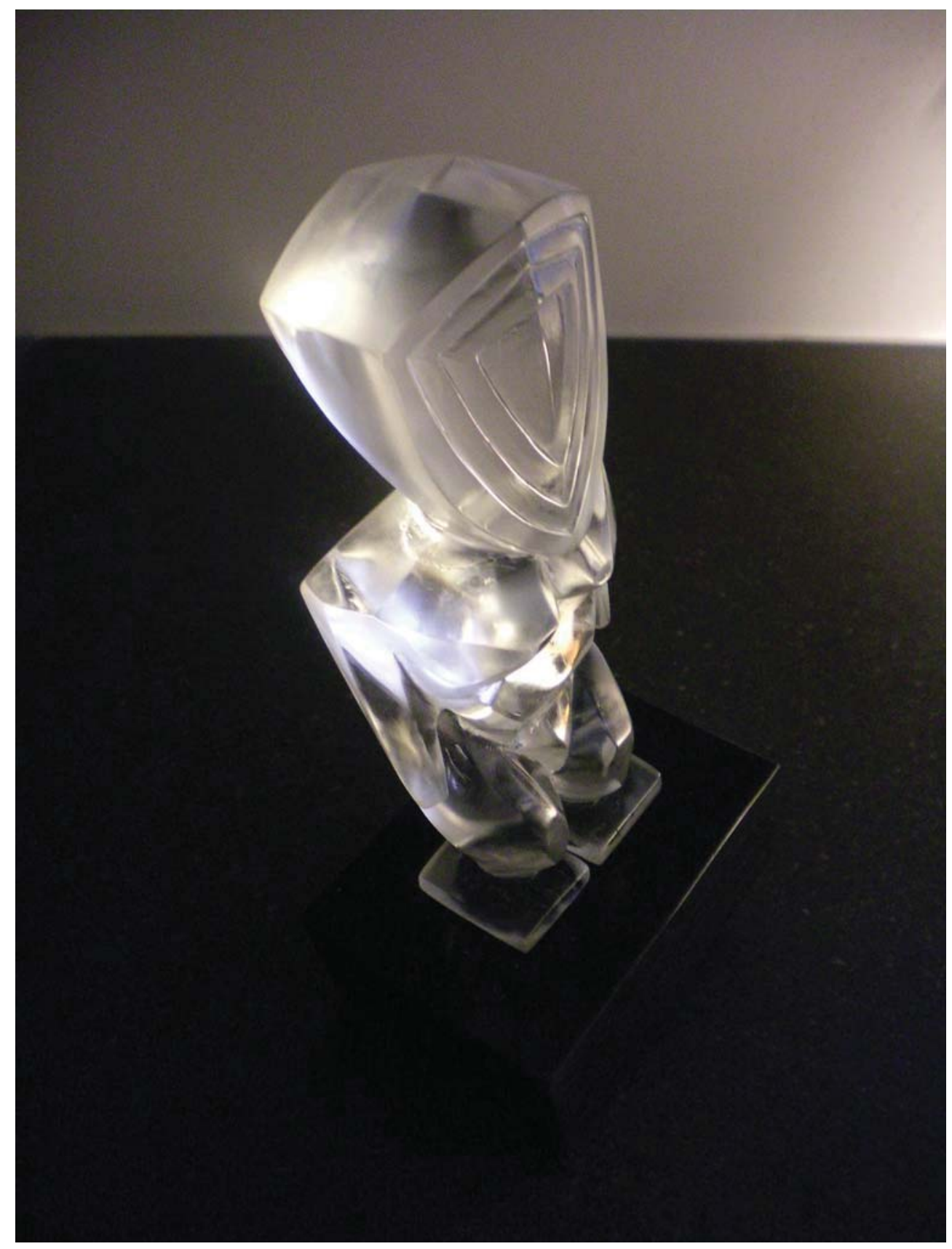

'Aho'eitu Ma'ama, by Visesio Siasau, 2009.

Perspex on Corian. $26 \mathrm{~cm}$ X I I. $5 \mathrm{~cm}$. Collection of the artist.

Langi (the head of a deity) signifies death and the knowledge of ono'aho (the past), which lights our journey into the future. Photo by Serene Tay. 


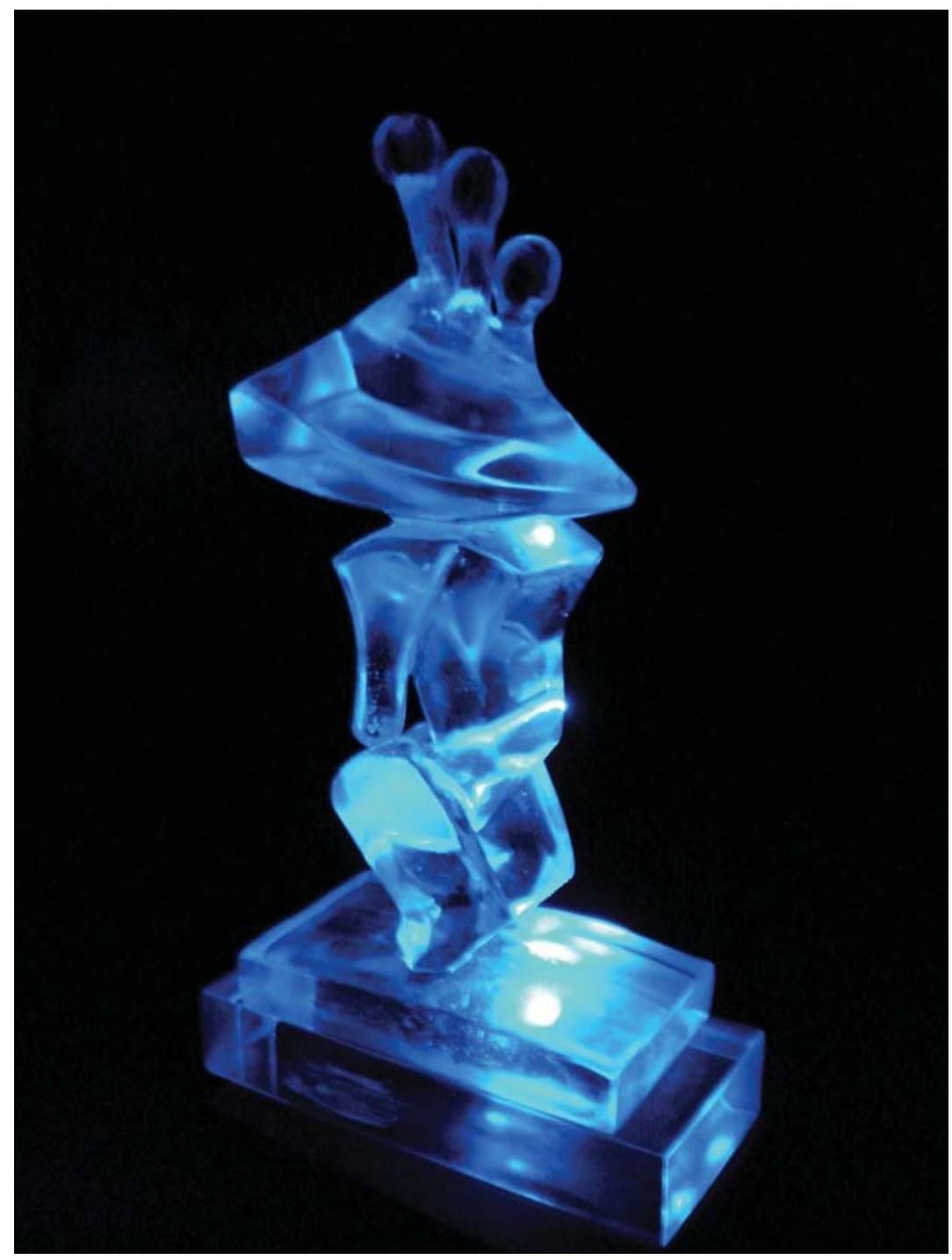

'Aho'eitu, by Visesio Siasau, 2009.

Perspex. $30 \mathrm{~cm}$ X I $5 \mathrm{~cm}$. Collection of the artist.

'Aho'eitu represents a meeting point for spiritual knowledge and the knowledge that Tongans use to operate in the material world. This epistemology was passed down to ma'ama (earth) through Tangaloa when he impregnated 'Ilaheva, the mother of 'Aho'eitu. Photo by Serene Tay. 


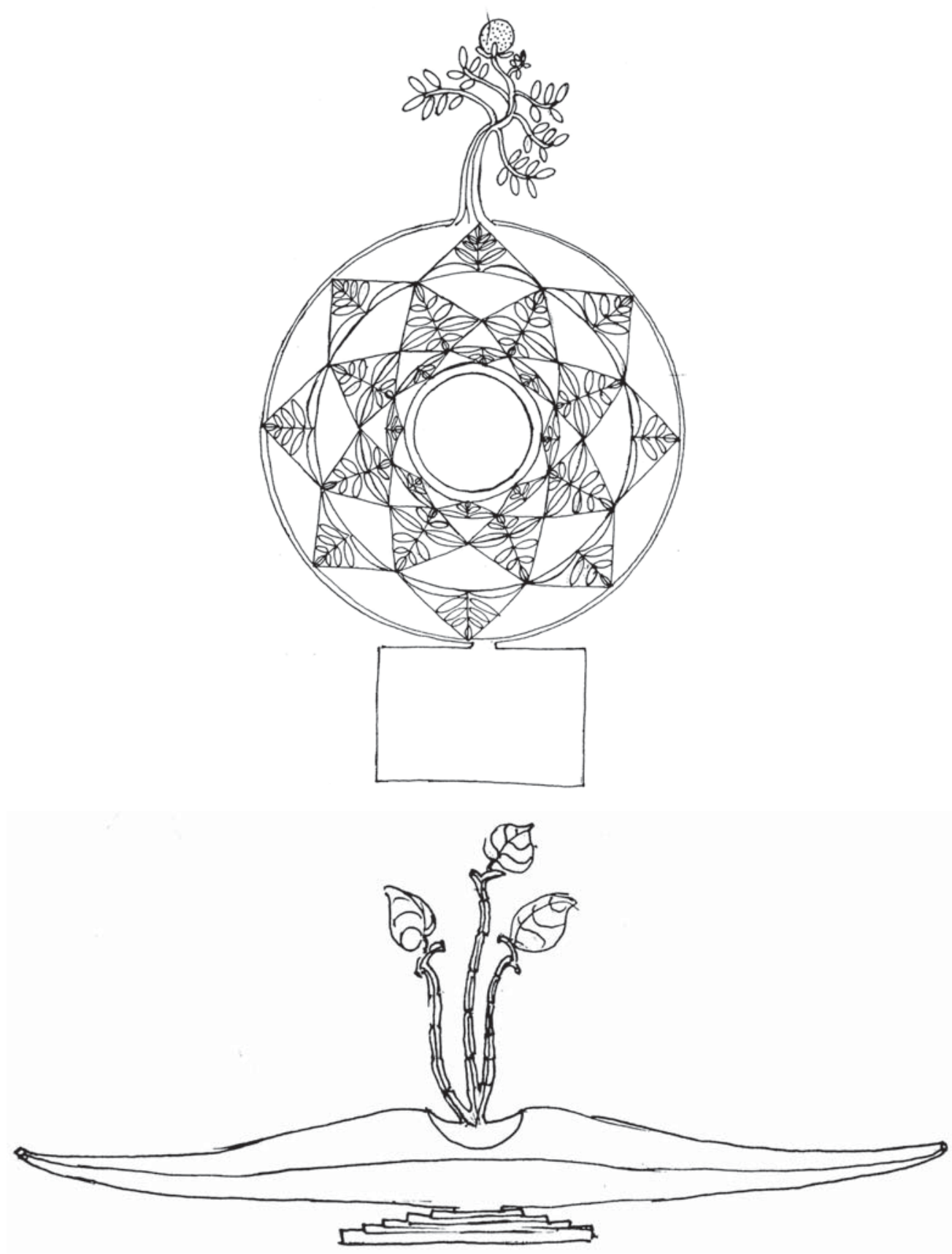

Mo'ui (Life), by Visesio Siasau, 2013.

Fonua (Umbilical Cord), Visesio Siasau, 2013.

Graphite on paper. Collection of the artist.

These sketches for a sculpture series are reflections on the harmony between me'a mo'ui (living things) and me'a mate (nonliving things). 


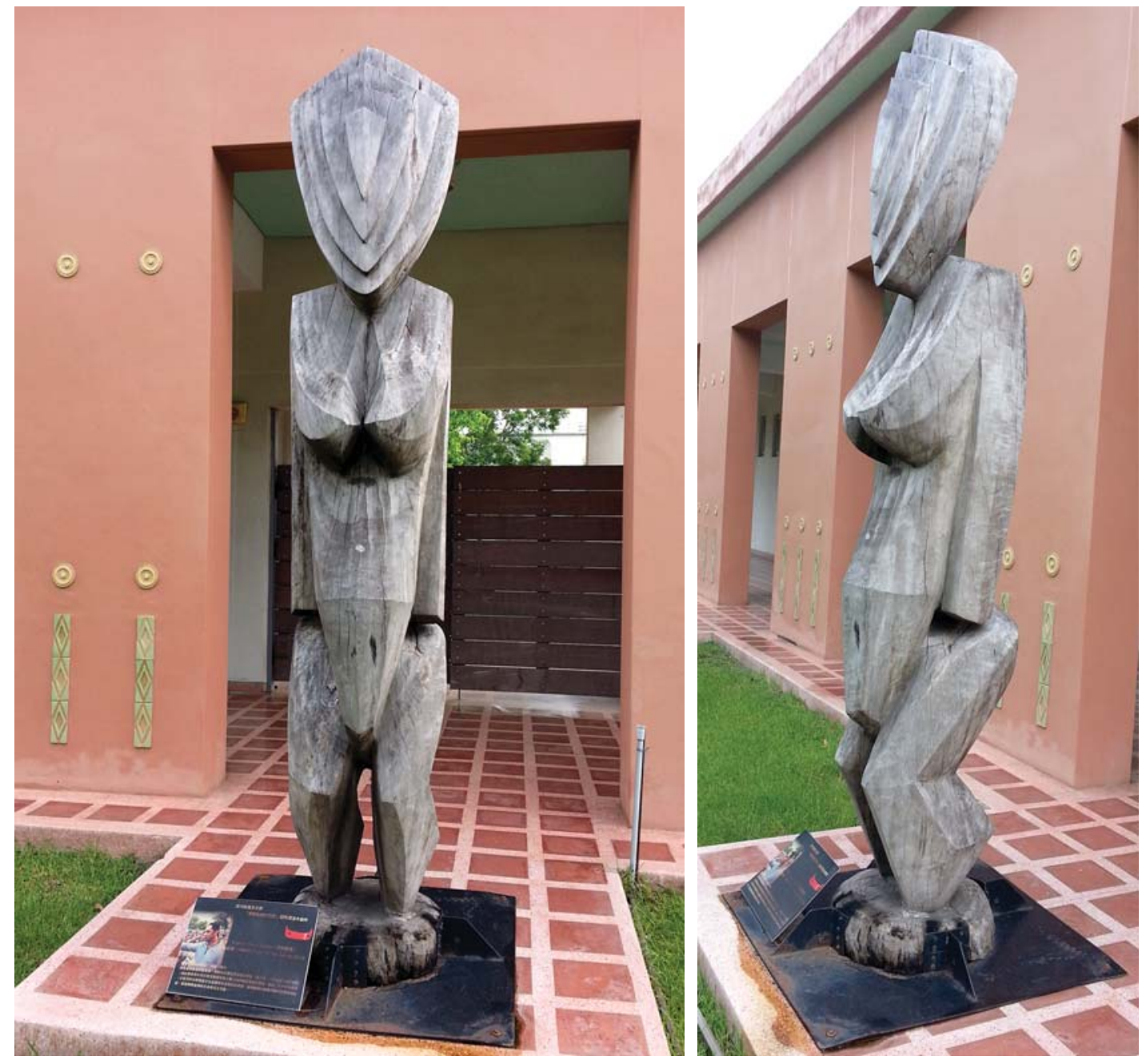

Tamahā Tai Tung, by Visesio Siasau, 20 Iо.

Wood. 3 meters tall.

Proto-Polynesian people departed from Asia thousands of years ago. This sculpture, representing a Tamahā (sacred child), was carved while Visesio Siasau was on residency in Taiwan, and it is now in the collection of the National Museum of Prehistory in Taitung City, Taiwan. Photos courtesy of the Taitung County Government. 

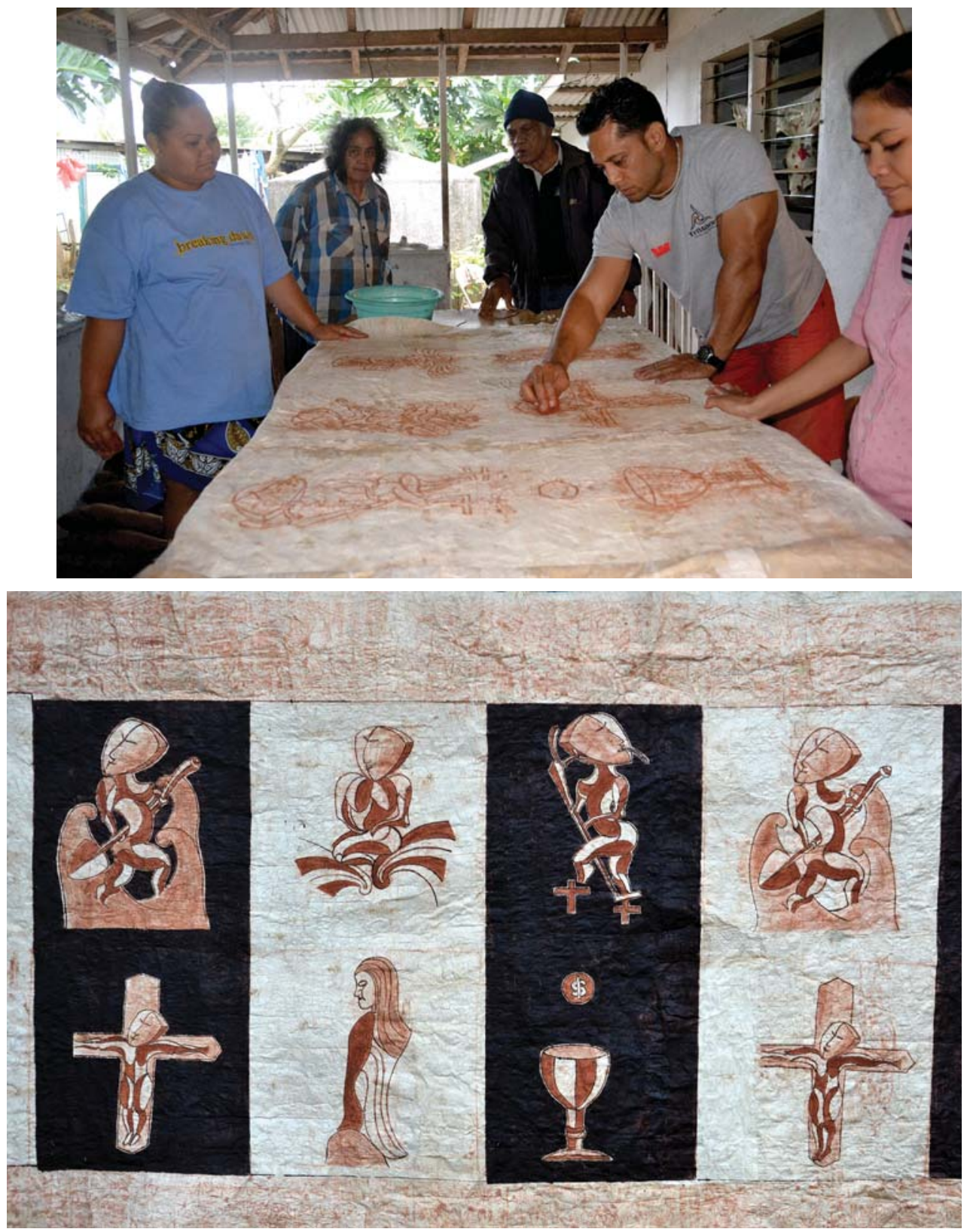

Ngatu, by Visesio Siasau and family members, 2013.

Paper mulberry bark (ngatu) and natural dyes. $107 \mathrm{~cm} \times 357 \mathrm{~cm}$.

For this work, Visesio Siasau learned to make ngatu from family members and added forms to signify Tongan heritage and cultural values offset by symbols of the diverse values in modern Tonga. Photos by Serene Tay. 